\title{
PENGARUH JOB INSECURITY, KEPUASAN KERJA, DAN STRES KERJA TERHADAP TURNOVER INTENTION PADA PT BPR ARTHA PRIMA PERKASA PULAU BATAM
}

\author{
Regina Desvarani ${ }^{1}$, Sastra Tamami ${ }^{2}$ \\ Fakultas Ekonomi, Universitas Riau Kepulauan, Pulau Batam \\ Email : sastrabons@gmail.com²
}

\section{ABSTRACT}

The purpose of this study was to determine the effect of Job Insecurity, Job Satisfaction, Job Stress on Turnover Intention at PT BPR Artha Prima Perkasa. This study used a quantitative method by distributing questionnaires to 32 employees who work at PT BPR Artha Prima Perkasa. Samples were taken by saturated sampling techniques. The data analysis method used is quantitative analysis, namely reliability test and validity test, classic assumption test, $T$ test and $F$ test, coefficient of determination and multiple linear regression analysis.

Based on the results of data analysis, it shows that: Job Insecurity variable has a significant effect on Turnover Intention with $T$ sig value of $0,000<0,05$, job satisfaction variable shows no effect on Turnover Intention with $T$ sig value of 0,624 $<0,05$ and Job stress has a significant effect on Turnover Intention with a $T$ sig value of $0,000<0,05$. Based on the $F$ test calculation, together with Job Insecurity, Job Satisfaction, Job Stress has a significant effect on Turnover Intention with F sig 0,000<0,05.

Keywords : Job Insecurity, Job Satisfaction, Job Stress, Turnover Intention

\section{PENDAHULUAN}

\subsection{Latar Belakang}

Seiring dengan pertumbuhan ekonomi, peningkatan pertumbuhan bank di Batam seperti saat ini menimbulkan persaingan yang ketat dalam memberikan pelayanan dan produk yang terbaik. Perusahaan yang mampu bertahan adalah perusahaan yang berhasil membangun keunggulan kompetitif dan memiliki kinerja yang baik.

PT BPR Artha Prima Perkasa merupakan perusahaan yang bergerak dibidang Perbankan yang sudah berdiri selama lebih dari 10 tahun. Dimana dalam mewujudkan misi dan visi perusahaan, terkadang perusahaan menghadapi permasalahan pada bidang pengelolaan sumber daya manusianya, terutama yang berkaitan dengan kinerjanya. Tingkat kompetisi yang tinggi menuntut PT BPR Artha Prima Perkasa harus mengoptimalkan sumber daya manusia yang dimiliknya yaitu para karyawan. Hal tersebutlah yang membuat pimpinan PT BPR Artha Prima Perkasa sadar akan nilai investasi karyawan sebagai sumber daya manusia, dimana saat ini mengumpulkan karyawan yang cakap dan berkinerja baik semakin suit dilakukan, terlebih lagi mempertahankan yang sudah ada. Mereka harus memprioritaskan untuk menemukan, mempekerjakan, memotivasi, melatih, mengembangkan karyawan yang paling dekat dengan peforma yang dikehendaki, hingga mempertahankan karyawan yang berkualitas. Disinilah dituntut adanya peranan penting manajemen sumber daya manusia dalam sebuah perusahaan. Pihak perusahaan PT BPR Artha Prima Perkasa perlu memotivasi para karyawan untuk mencapai tujuan secara efektif, dengan senantiasa melakukan investasi untuk melakukan penerimaan, penyeleksian, dan mempertahankan karyawan potensial agar tidak berdampak pada turnover (perpindahan kerja) karyawan.

\subsection{Perumusan Masalah}

1. Apakah job insecurity berpengaruh terhadap turnover intention pada PT BPR Artha Prima Perkasa?

2. Apakah kepuasan kerja berpengaruh terhadap turnover intention pada PT BPR Artha Prima Perkasa? 
3. Apakah stres kerja berpengaruh terhadap turnover intention pada PT BPR Artha Prima Perkasa?

4. Apakah job insecurity, kepuasan kerja, dan stress kerja berpengaruh secara simultan terhadap turnover intention pada PT BPR Artha Prima Perkasa?

\subsection{Tujuan Penelitian}

1. Untuk mengetahui apakah job insecurity berpengaruh terhadap turnover intention pada PT BPR Artha Prima Perkasa.

2. Untuk mengetahui apakah kepuasan kerja kerja berpengaruh terhadap turnover intention pada PT BPR Artha Prima Perkasa.

3. Untuk mengetahui apakah stres kerja berpengaruh terhadap turnover intention pada PT BPR Artha Prima Perkasa.

4. Untuk mengetahui apakah job insecurity, kepuasan kerja, dan stres kerja berpengaruh secara simultan terhadap turnover intention pada PT BPR Artha Prima Perkasa.

\section{TINJAUAN PUSTAKA}

\subsection{Job Insecurity}

Menurut Greenhalgh dalam Alifian (2015) ketidakamanan kerja merupakan perasaan khawatir dan ketidakberdayaan karyawan dalam menghadapi berbagai ancaman yang mungkin mengakibatkan hilangnya sebagian atau keseluruhan aspekaspek pekerjaan.

\subsection{Kepuasan Kerja}

Richard (2012) menegaskan bahwa kepuasan kerja berhubungan dengan perasaan atau sikap seseorang mengenai pekerjaan itu sendiri, gaji, kesempatan promosi atau pendidikan, pengawasan, rekan kerja, beban kerja dan lain-lain. la melanjutkan pernyataanya bahwa kepuasan kerja berhubungan dengan sikap seeorang mengenai kerja, dan ada beberapa alasan praktis yang membuat kepuasan kerja merupakan konsep yang penting bagi pemimpim.

\subsection{Stres Kerja}

Menurut Mangkunegara (2012), menyatakan bahwa stres kerja adalah perasaan yang menekan atau merasa tertekan yang dialami karyawan dalam menghadapi pekerjaan. Stres kerja ini dapat menimbulkan emosi tidak stabil, perasaan tidak tenang, suka menyendiri, sulit tidur, merokok berlebihan, tidak bisa rileks, cemas, tegang, gugup, tekanan darah meningkat dan mengalami gangguan pencernaan. Stres kerja diukur oleh beberapa hal, antara lain: beban kerja yang terlalu berat, waktu kerja yang mendesak, kualitas pengawasan kerja yang rendah, iklim kerja yang tidak sehat, otoritas kerja yang tidak memadai yang berhubungan dengan tanggung jawab, konflik kerja, serta perbedaan nilai antara karyawan dengan pemimpin.

\subsection{Turnover Intention}

Dalam Sandi (2014), turnover intentions diindikasikan sebagai sikap individu yang mengacu pada hasil evaluasi mengenai kelangsungan hubungannya dengan organisasi dimana dirinya bekerja dan belum terwujud dalam bentuk tindakan pasti. Turnover lebih mengarah pada kenyataan akhir yang dihadapi organisasi berupa jumlaah karyawan yang meninggalkan organisasi. Dalam Sari (2014), intensi adalah niat atau keinginan yang timbul pada individu untuk melakukan sesuatu. Sementara turnover adalah berhentinya atau penarikan diri seseorangkaryawan dari tempat bekerja. Dengan demikian, turnover intention (intensi keluar) adalah kecenderungan atau niat karyawan untuk berhenti bekerja dari pekerjaannya.

\subsection{Hipotesis}

1. Diduga job insecurity berpengaruh terhadap turnover intention pada PT BPR Artha Prima Perkasa.

2. Diduga kepuasan kerja berpengaruh terhadap turnover intention pada PT BPR Artha Prima Perkasa.

3. Diduga stress kerja berpengaruh terhadap turnover intention pada PT BPR Artha Prima Perkasa.

4. Diduga job insecurity, kepuasan kerja, dan stress kerja berpengaruh secara simultan 
terhadap turnover intention pada PT BPR Artha Prima Perkasa.

\section{METODOLOGI PENELITIAN}

\subsection{Jenis Penelitian}

Penelitian ini adalah penelitian survey dengan pendekatan kuantitatif bersifat kausal dengan menggunakan dua sumber data yaitu primer dan sekunder. Data primer merupakan data yang diperoleh secara langsung dari sumber asli (tanpa melalui perantara).

\subsection{Populasi dan Sampel}

Populasi dalam penelitian ini adalah karyawan dan karyawati pada perusahaan PT BPR Artha Prima Perkasa di Batam yang berjumlah sebanyak 32 orang karyawan. Karena jumlah populasinya tidak lebih besar dari 100 orang, maka penulis mengambil sampel $100 \%$ dari jumlah populasi yang ada yaitu sebanyak 32 orang.

\subsection{Teknik Pengumpulan Data}

Data dalam penelitian ini adalah data primer yang merupakan data kuesioner yang diperoleh langsung dari pengisian kuesioner oleh karyawan PT BPR Artha Prima Perkasa di Batam. Sedangkan data sekunder adalah data penelitian yang diperoleh secara tidak langsung melalui media perantara (diperoleh dan dicatat oleh pihak lain). Data sekunder dalam penelitian ini adalah data tentang perusahaan meliputi: Gambaran umum perusahaan, struktur organisasi, dan informasi lainnya Adapun yang menjadi tempat penelitian ini di PT BPR Artha Prima Perkasa, Komplek Nagoya Newtown Blok E No. 06-07 Pulau Batam.

\subsection{Teknik Analisis Data}

Teknik analisis data yang digunakan dalam penelitian ini adalah analisis kuantitatif terdiri atas Uji Validitas, Uji Reabilitas , Uji Normalitas, Uji Multikolinearitas, Uji Heteroskedastisitas, Uji Analisis Regresi Linier Berganda, Uji T (Parsial), Uji F (Simultan), Uji Analisis Koefisien Determinasi $\left(R^{2}\right)$

\section{HASIL PENELITIAN DAN PEMBAHASAN}

\subsection{Hasil Uji Validitas}

Tabel 1.

Hasil Uji Validitas Job Insecurity

\begin{tabular}{ccccc}
\hline Variabel & Item & r Hitung & r Tabel & Keterangan \\
\hline & X1.1 & 0,739 & 0,349 & Valid \\
Job Insecurity & X1.2 & 0,386 & 0,349 & Valid \\
(X1) & X1.3 & 0,697 & 0,349 & Valid \\
& X1.4 & 0,729 & 0,349 & Valid \\
& X1.5 & 0,814 & 0,349 & Valid \\
\hline \multirow{4}{*}{ Kepuasan Kerja } & X2.1 & 0,814 & 0,349 & Valid \\
(X2) & X2.2 & 0,729 & 0,349 & Valid \\
& X2.3 & 0,500 & 0,349 & Valid \\
& X2.5 & 0,432 & 0,349 & Valid \\
\hline \multirow{2}{*}{ Stres Kerja } & X3.1 & 0,443 & 0,349 & Valid \\
(X3) & X3.2 & 0,445 & 0,349 & Valid \\
& X3.3 & 0,728 & 0,349 & Valid \\
& X3.4 & 0,362 & 0,349 & Valid \\
\hline \multirow{2}{*}{ Turnover } & X3.5 & 0,560 & 0,349 & Valid \\
insention & Y.1 & 0,545 & 0,349 & Valid \\
(Y) & Y.3 & 0,598 & 0,349 & Valid \\
& Y.4 & 0,744 & 0,349 & Valid \\
& Y.5 & 0,819 & 0,349 & Valid \\
\hline Sumber :Hasil & 0,413 & 0,349 & Valid \\
\hline
\end{tabular}

Sumber : Hasil pengolahan data SPSS V.20, 2018 
Hasil uji validitas seperti ditampilkan pada tabel diatas menunjukkan bahwa semua butir pernyataan mempunyai nilai $r$ hitung $>r$ tabel, dengan taraf signifikan $\alpha=0,05$ dan nilai $r$ tabel nya sebesar 0,349 dapat disimpulkan bahwa semua pernyataan pada variabel $\mathrm{X} 1$, $\mathrm{X} 2$, dan X3 dinyatakan valid.

\subsection{Hasil Uji Reabilitas}

Tabel 2.

Hasil Uji Reabilitas

\begin{tabular}{lcccc}
\hline \multicolumn{1}{c}{ Variabel } & Alpha Cronbach & N Off Item & r Tabel & Keterangan \\
\hline Job Insecurity (X1) & 0,750 & 5 & 0,349 & Reliabel \\
Kepuasan Kerja (X2) & 0,726 & 5 & 0,349 & Reliabel \\
Stres Kerja (X3) & 0,553 & 5 & 0,349 & Reliabel \\
Turnover insention (Y) & 0,672 & 5 & 0,349 & Reliabel \\
\hline
\end{tabular}

Sumber : Hasil pengolahan data SPSS V.20, 2018

Dari tabel di atas dapat dilihat bahwa $R$ alpha dari masing - masing variabel $X 1, X 2$, $X 3$ dan $Y$ lebih besar dari 0,349. Dengan demikian dapat disimpulkan bahwa data yang diuji tersebut dinyatakan reliabel.

\subsection{Hasil Uji Normalitas}

Tabel 3.

Hasil Uji One-Sample Kolmogorov-Smirnov Test One-Sample Kolmogorov-Smirnov Test

\begin{tabular}{llr}
\hline & & Unstandardized Residual \\
\hline $\mathrm{N}$ & & 32 \\
\hline \multirow{2}{*}{ Normal Parameters a.b } & Mean & $0 \mathrm{E}-7$ \\
& Std. Devitation &, 67045079 \\
\hline \multirow{3}{*}{ Most Extreme Differences } & Absolute &, 106 \\
& Positive &, 106 \\
& Negative &,- 074 \\
\hline Kolmogorov-Smirnov Z & &, 598 \\
\hline Asymp. Sig (2-tailed) & &, 867 \\
\hline
\end{tabular}

Berdasarkan hasil uji Kolmogorovsmirnov, diketahui nilai Asymp. Sig. (2-tailed) sebesar 0,867 >0,05 (alpha) sehingga dapat disimpulkan bahwa data mempunyai sebaran yang normal.

\subsection{Hasil Uji Multikolinearitas}

Tabel 4.

Hasil Uji Multikolinearitas Coefficientsa

\begin{tabular}{|c|c|c|c|c|c|c|c|c|}
\hline & \multirow[t]{2}{*}{ Model } & \multicolumn{2}{|c|}{$\begin{array}{l}\text { Unstandardized } \\
\text { Coefficients }\end{array}$} & \multirow{2}{*}{$\begin{array}{c}\text { Standardized } \\
\text { Coefficients } \\
\text { Beta }\end{array}$} & \multirow[t]{2}{*}{$\mathrm{T}$} & \multirow[t]{2}{*}{ Sig. } & \multicolumn{2}{|c|}{ Collinearity } \\
\hline & & $\mathrm{B}$ & Std Error. & & & & Tolerance & VIF \\
\hline \multirow{4}{*}{1} & (Constant) &,- 953 & 1,018 & &,- 946 & ,352 & & \\
\hline & Job Insecurity & ,450 & , 103 & ,482 & 4,457 &, 000 & ,214 & 4,669 \\
\hline & Kepuasan kerja & ,035 & ,071 & ,038 & ,496 & 624 & ,436 & 2,294 \\
\hline & Stres Kerja & , 596 & ,099 & , 509 & 6,000 & ,000 & 348 & 2,872 \\
\hline
\end{tabular}


Tabel menunjukkan menunjukkan bahwa nilai VIF untuk variabel X1, X2, dan X3 masing-masing sebesar 4,669; 2,294; dan 2,872 sehingga dapat disimpulkan bahwa dalam model regresi tidak terdapat gejala multikolinearitas antar variabel bebas karena nilai VIF nya lebih kecil dari 10 yang berarti bahwa semua variabel tersebut dapat digunakan sebagai variabel yang saling independen.

\subsection{Hasil Uji Heteroskedastisitas}

Tabel 5.

Hasil Uji Heteroskedastisitas Glejser Coefficientsa

\begin{tabular}{|c|c|c|c|c|c|c|}
\hline & \multirow[t]{2}{*}{ Model } & \multicolumn{2}{|c|}{$\begin{array}{c}\text { Unstandardized } \\
\text { Coefficients }\end{array}$} & \multirow{2}{*}{$\begin{array}{c}\begin{array}{c}\text { Standardized } \\
\text { Coefficients }\end{array} \\
\text { Beta } \\
\end{array}$} & \multirow[t]{2}{*}{ T } & \multirow[t]{2}{*}{ Sig. } \\
\hline & & $B$ & Std Error. & & & \\
\hline \multirow{4}{*}{1} & (Constant) & 1,193 &, 552 & & 2,161 & ,039 \\
\hline & Job Insecurity & ,002 & ,056 & ,013 & ,032 & ,975 \\
\hline & Kepuasan kerja &,- 029 & ,038 &,- 208 & - & ,460 \\
\hline & Stres Kerja &,- 012 & ,054 &,- 070 &,- 224 & ,824 \\
\hline
\end{tabular}

a. Dependent variable : abs_res

Sumber : Hasil pengolahan data SPSS V.20, 2018

Hasil pengujian Park Gleyser melihat nilai probabilitas dengan signifikansi > nilai alpha $(0,05)$ maka model tidak mengalami heteroskedastisitas (Wibowo, 2012). Pada Tabel 4.13 diketahui bahwa nilai probabilitas atau signifikansi dari masing-masing variabel 0,$975 ; 0,460$; dan 0,824 lebih besar dari nilai alpha $(0,05)$ maka dapat disimpulkan bahwa dalam model regresi tidak terdapat gejala heteroskedastisitas.

\subsection{Hasil Uji Analisis Regrensi Linier Berganda}

Tabel 6.

Hasil Uji Analisis Regrensi Linier Berganda Coefficientsa

\begin{tabular}{|c|c|c|c|c|c|c|}
\hline & \multirow[t]{2}{*}{ Model } & \multicolumn{2}{|c|}{$\begin{array}{c}\text { Unstandardized } \\
\text { Coefficients }\end{array}$} & \multirow{2}{*}{$\begin{array}{c}\text { Standardized } \\
\text { Coefficients } \\
\text { Beta }\end{array}$} & \multirow[t]{2}{*}{$\mathrm{T}$} & \multirow[t]{2}{*}{ Sig. } \\
\hline & & $B$ & Std Error. & & & \\
\hline \multirow{4}{*}{1} & &,- 963 & 1,018 & &,- 946 & ,352 \\
\hline & Job & ,460 & ,103 & ,482 & 4,457 &, 000 \\
\hline & Kepuasan kerja & ,035 & ,071 & ,038 & ,496 & ,624 \\
\hline & Stres Keria & 596 & 099 & .509 & 6,000 & 000 \\
\hline
\end{tabular}

a. Dependent variable : Turnover Intention

Sumber : Hasil pengolahan data SPSS V.20, 2018

Berdasarkan Tabel diatas dapat diperoleh persamaan regresi linear berganda sebagai berikut: $Y=-963+0,460 X 1+0,035 X 2$ $+0,596 \times 3+e$

\section{a. Hasil Uji T (Parsial)}

Hasil dari tabel menunjukkan bahwa variabel Job Insecurity (X1) nilai t hitung 4,457 $>t$ tabel 2,048 dan nilai signifikan $0,000<0,05$ sehingga keputusan yang diambil adalah $\mathrm{H}_{\mathrm{o}}$ ditolak dan $\mathrm{H}_{\mathrm{a}}$ diterima. Hal ini berarti bahwa Job Insecurity berpengaruh secara signifikan terhadap turnover intention.

$$
\text { Variabel kepuasan kerja (X2) }
$$
menunjukkan nilai t hitung $0,496<t$ tabel 2,048 dan nilai signifikan $0,624>0,05$ sehingga keputusan yang diambil adalah $\mathrm{H}_{0}$ diterima dan $\mathrm{H}_{\mathrm{a}}$ ditolak. Hal ini berarti bahwa kepuasan kerja tidak berpengaruh dan tidak signifikan terhadap Turnover Intention. 
Variabel stres kerja (X3) nilai t hitung 6,000 >t tabel 2,048 dan nilai signifikan 0,000 $<0,05$ sehingga keputusan yang diambil adalah $\mathrm{H}_{0}$ ditolak dan $\mathrm{H}_{a}$ diterima. Hal ini berarti bahwa stres kerja berpengaruh secara signifikan terhadap turnover intention.

Tabel 7.

Hasil Uji T (Parsial) Coefficients ${ }^{a}$

\begin{tabular}{|c|c|c|c|c|c|c|}
\hline & \multirow[t]{2}{*}{ Model } & \multicolumn{2}{|c|}{$\begin{array}{l}\text { Unstandardized } \\
\text { Coefficients }\end{array}$} & \multirow{2}{*}{$\begin{array}{c}\text { Standardized } \\
\text { Coefficients } \\
\text { Beta }\end{array}$} & \multirow[t]{2}{*}{$\mathrm{T}$} & \multirow[t]{2}{*}{ Sig. } \\
\hline & & $B$ & Std Error. & & & \\
\hline \multirow{4}{*}{1} & (Constant) &,- 963 & 1,018 & &,- 946 & ,352 \\
\hline & Job Insecurity & ,460 & 103 & ,482 & 4,457 &, 000 \\
\hline & Kepuasan kerja & ,035 & ,071 & ,038 & ,496 & 624 \\
\hline & Stres Kerja &, 596 & ,099 &, 509 & 6,000 &, 000 \\
\hline
\end{tabular}

a. Dependent variable : Turnover Intention

Sumber : Hasil pengolahan data SPSS V.20, 2018

b. Uji F (Simultan)

Tabel 8.

Hasil Uji F ANOVAa

\begin{tabular}{|c|c|c|c|c|c|c|}
\hline & Model & Sum of Squares & Df & Mean Square & $\mathrm{F}$ & Sig. \\
\hline \multirow{3}{*}{1} & Regression & 185,034 & 3 & 61,679 & 123,935 &, $000^{b}$ \\
\hline & Residual & 13,935 & 28 & ,498 & & \\
\hline & Total & 198,969 & 31 & & & \\
\hline
\end{tabular}

a. Dependent variable : Turnover Intention

b. Predictors : (Constant), Stres kerja, Kepuasan kerja, Job Insecurity

Sumber : Hasil pengolahan data SPSS V.20, 2018

Hasil uji $F$ memperlihatkan nilai $F$ sebesar 123.935 ( $F$ hitung) $>2,81$ ( $F$ tabel) dan nilai signifikansi sebesar $0,000<0,05$ sehingga keputusan yang diambil adalah $\mathrm{H}_{0}$ ditolak dan $\mathrm{H}_{\mathrm{a}}$ diterima. Hasil ini menunjukkan bahwa

c. Koefisien Determinasi $\left(R^{2}\right)$ variabel Job Insecurity (X1), Kepuasan kerja (X2), dan Stres Kerja (X3) mempunyai pengaruh yang positif dan signifikan terhadap variabel Turnover Intention $(\mathrm{Y})$.

Tabel 9.

Hasil Uji Koefisien Determinasi Model Summary

\begin{tabular}{ccrrr}
\hline Model & $\mathrm{R}$ & $\mathrm{R}$ Square & $\begin{array}{c}\text { Adjusted R } \\
\text { Aquare }\end{array}$ & $\begin{array}{c}\text { Std. Error of the } \\
\text { Estimate }\end{array}$ \\
\hline 1 &, $964^{\mathrm{a}}$ &, 930 &, 922 &, 705 \\
\hline
\end{tabular}

a. Predictors : (Constant), Stres kerja, Kepuasan kerja, Job Insecurity

Sumber : Hasil pengolahan data SPSS V.20, 2018

Hasil Uji Koefisien Determinasi memperlihatkan nilai $R$ Square sebesar 0,922. Hasil pengujian nilai Adjusted $R$ Square sebesar 0,922 atau $92,2 \%$ dari turnover intention dapat dipengaruhi oleh job insecurity
$(X 1)$, kepuasan kerja $\left(X_{2}\right)$, dan stres kerja $\left(X_{3}\right)$. Sisanya $7,8 \%$ turnover intention dipengaruhi oleh variabel-variabel lain yang tidak dijelaskan dalam penelitian ini. 


\section{SIMPULAN DAN SARAN}

\subsection{Simpulan}

Berdasarkan hasil penelitian dan pembahasan yang telah dilakukan pada bab sebelumnya, maka dapat disimpulkan bahwa secara parsial Job insecurity berpengaruh secara positif dan signifikan terhadap turnover intention PT BPR Artha Prima Perkasa. Stres kerja berpengaruh terhadap turnover intention PT BPR Artha Prima Perkasa. Sedangkan Kepuasan kerja tidak berpengaruh terhadap turnover intention PT BPR Artha Prima Perkasa.

Hasil uji $F$ memperlihatkan nilai $F$ sebesar 123.935 ( $F$ hitung) > 2,81 ( $F$ tabel), diperkuat dengan nilai probabilitas signifikansi sebesar $0,000<0,05$ sehingga keputusan yang diambil adalah $\mathrm{H}_{0}$ ditolak dan $\mathrm{H}_{\mathrm{a}}$ diterima. Hasil ini menunjukkan bahwa variabel Job Insecurity, Kepuasan kerja, dan Stres Kerja berpengaruh secara simultan terhadap turnover intention PT BPR Artha Prima Perkasa.

\subsection{Saran}

PT BPR Artha Prima Perkasa harus memperhatikan mengenai Job Insecurity dalam perusahaan yang dapat menjadi pertimbangan dalam menurunkan turnover intention. Sebaiknya PT BPR Artha Prima Perkasa agar lebih memperhatikan stres kerja yang dialami karyawan dalam perusahaan untuk dapat menurunkan turnover intention. Kepuasan kerja merupakan bagian penting yang perlu diperhatikan. PT BPR Artha Prima Perkasa menanggapi serius persoalan tentang turnover intention. Dengan harapan tingkat turnover intenion dapat menurun setiap tahunnya. Terutama yang berkaitan dengan job insecurity, kepuasan kerja, dan stres kerja yang telah di teliti di PT BPR Artha Prima Perkasa

\section{DAFTAR PUSTAKA}

Alifian, Ima. 2015. Analisis Pengaruh Job Insecurity, Kepuasan Kerja, dan Komitmen Organisasi Terhadap Keinginan Berpindah Karyawan (Studi pada Karyawan Outsourcing PT POS Indonesia Cabang Kudus. Semarang: Universitas Diponegoro.
Alshitri, Khalid I. (2013). An Investigation of Factors Affecting Job Satisfaction among R\&D Center Employees in Saudi Arabia. Journal of Human Resources Management Research. Vol. 2013. Article ID 279369, DOI: 10.5171/2013.279369. 1-10

Cahyadinanto, SanjokoDeny. 2015 "Analisis Pengaruh Stres Kerja Dan Lingkungan Kerja Non Fisik Terhadap Kepuasan Kerja Dan Dampaknya Terhadap Turnover Intention Karyawan Pada Karyawan Pabrik PT. Panverta Cakrakencana Pandaan". Semarang: Universitas Diponegoro.

Dwiningtyas. 2015. Pengaruh Kepuasan Kerja, Stres Kerja dan Lingkungan Kerja Terhadap Turnover Intention Pada Karyawan CV. Aneka IImu Semarang. Semarang: Universitas Negeri Semarang.

Hanafiah, Mohammad. 2014. Pengaruh Kepuasan Kerja dan Ketidakamanan Kerja (Job Insecurity) dengan Intensi Pindah Kerja (Turnover) pada Karyawan PT. Buma Desa Suaran Kecamatan Sambaliung Kabupaten Berau. E-Journal Psikologi, 1 (3), pp: 303-312.

Herlambang, Muhammad Garin, dan Fajrianthi. 2014. Pengaruh Career Growth dan Job Insecurity terhadap Intensi Turnover pada Pegawai Kontrak di Instansi $X$. Jurnal Psikologi Industri dan Organisasi, 3(3), pp: 183-192.

Irvianti, Laksmi Sito Dwi dan Renno Eka Verina. 2015. Analisis Pengaruh Stres Kerja, Beban Kerja, dan Lingkungan Kerja Terhadap Turnover Intention Karyawan pada PT XL Axiata Tbk Jakarta. Binus Business Review Vol. 6 No.1.

Issa, Dua'a Abdul Rahim Mohammad. Fais Ahmad, dkk. 2013. "Job Satisfaction and Turnover Intention Based on Sales Person Standpoint". Dalam Middle- 94 East Journal of Scientific Research, Volume 14 No. 4 Hal. 525-531 Malaysia: IDOSI Publications. 
Kekesi, Elias Kodjo dan Agyemang Collins Badu. 2014. Perceived Joblnsecurity and Pyschological Distres: The Moderating Role of Work Values. International Journal of Management, Economic and Social Sciences, Vol. 3 (1):18-35.

Mangkunegara, A.P. (2012). "Evaluasi Kinerja SDM". Bandung: PT Rafika Aditama.

Martini, Elven dan Lieke E.M. Waluyo. 2014. Pengaruh Jangka Pendek Job Insecurity dan Kompensasi Terhadap Kepuasan Kerja Karyawan Outsourcing di PT Askes (Persero) Kantor Pusat. Jurnal Psikologi Volume 2, No. 7 Desember 2014

Minanti, Puput. 2015. Pengaruh Job Insecurity, Komitmen Organisasi dan Kepuasan Kerja terhadap Turnover Intentionmelalui Stres Kerja (Studi pada sopir P.O Citrea Wisata Mandir (CWM) Jember). Jawa Timur: Universitas Jember.

Putra, I Gede Suwardiana, dan I Made Artha Wibawa. 2014. Pengaruh Stres Kerja dan Komitmen Organisasi terhadap Kepuasan Kerja berdasarkan Gender pada Warong Miyabi Bali. E-Jurnal Manajemen Universitas Udayana, pp: 2745-2766.

Richard L. Hughes, Robert C Ginnett, \& Gordon J Curphy, 2012, "Leadership Enhancing the Lessons of Experience - Memperkaya Pelajaran dari Pengalaman" Edisi 7. Jakarta: Salemba Humanika

Robbins, S.P dan Judge T.A. 2015. "Perilaku Organisasi". Jakarta: Salemba Empat.

Sandi, Freza Mahaztra. 2014. Analisis Pengaruh Kompensasi dan Job InsecurityTerhadap Turnover Intention (Studi Pada Guru SDIT Asy-Syaamil Bontang). Semarang: Universitas Diponegoro.

Sari, Rindi Nurlaila. 2014. Pengaruh Kepuasan Kerja, Stres Kerja, dan Komitmen Organisasi terhadap Turnover Intention (Studi pada pada Hotel lbis
Yogyakarta). Yogyakarta: Universitas Negeri Yogyakarta.

Septiani, Ni Ketut. dan I Komang Ardana. 2016. Pengaruh Job Inseuritydan Stres Kerja terhadap Turnover Intention. (Studi pada Hotel Asana Agung Putra Bali). Bali:Universitas Udayana.

Setiawan, I Nyoman Agus. 2016. Pengaruh Job Insecurity Terhadap Kepuasan Kerja dan Turnover Intention pada Karyawan Legian Village Hotel. E-Jurnal Manajemen Unud, Vol. 5, No.8, 2016: 4983-5012.

Siagian, Gunawan Aprizal. 2014. "Analisis Pengaruh Stres Kerja dan Kepuasan Kerja Terhadap Intention To Quit Perawat (Studi pada RSJD Dr. Amino Gondohutomo Semarang)". Semarang: Universitas Diponegoro.

Suciati, Andi Tri Haryono, dan Maria Magdalena Minarsih. 2015. Pengaruh Job Insecurity dan Stress kerja Terhadap Turnover Intention Pegawai pada karyawan PT. Berkat Abadi Surya Cemerlang Semarang (HO). Jurnal Manajemen Universitas Pandanaran, 1 (1), pp: 1-12.

Sugiyono. 2012. Metode Penelitian Bisnis. Bandung: Alfabeta.

Sunyoto, Dadang. 2013. "Teori, Kuesioner dan Proses Analisis Data Perilaku Organisasional" Jakarta: CAPS.

Wardani, Shanti Ike, Sutrisno, dan Rudy Eko Pramono. 2014. Pengaruh Job Insecurity Terhadap Turnover Intention Karyawan CV Putra Makmur Abadi Temanggung Jawa Tengah.llmu Administrasi Bisnis, Fakultas IImu Sosial dan IImu Politik, Universitas Jember (UNEJ). Artikel IImiah Hasil Penelitian Mahasiswa, pp: 1-7.

Wicaksono. Windu. 2016. Pengaruh Job Insecurity, Job Stress, dan Work Family Conflick terhadap Turnover Intention (Studi pada Perusahan CV. Batik Indah Rara Djonggrang). Yogyakarta: Universitas Muhammadiyah Yogyakarta. 
ISSN 2086-9592 